\title{
Inflammatory monocyte gene expression: trait or state marker in bipolar disorder?
}

\author{
K. Becking ${ }^{1,2^{*}+}$, B. C. M. Haarman ${ }^{2,3 \dagger}$, R. F. Riemersma van der Lek ${ }^{1,2}$, L. Grosse ${ }^{4}$, W. A. Nolen², S. Claes ${ }^{5}$, \\ H. A. Drexhage ${ }^{6}$ and R. A. Schoevers ${ }^{1,2}$
}

\begin{abstract}
Background: This study aimed to examine whether inflammatory gene expression was a trait or a state marker in patients with bipolar disorder (BD).

Methods: 69 healthy controls (HC), 82 euthymic BD patients and 8 BD patients with a mood episode (7 depressed, 1 manic) were included from the MOODINFLAME study. Six of the eight patients who had a mood episode were also investigated when they were euthymic ( 6 of the 82 euthymic patients). Of these participants the expression of 35 inflammatory genes was determined in monocytes using quantitative-polymerase chain reaction, of which a total gene expression score was calculated as well as a gene expression score per sub-cluster.

Results: There were no significant differences in inflammatory monocyte gene expression between healthy controls and euthymic patients. Patients experiencing a mood episode, however, had a significantly higher total gene expression score (10.63 \pm 2.58$)$ compared to healthy controls $(p=.004)$ and euthymic patients $(p=.009)$, as well as when compared to their own scores when they were euthymic $(p=.02)$. This applied in particular for the sub-cluster 1 gene expression score, but not for the sub-cluster 2 gene expression score.
\end{abstract}

Conclusions: Our study indicates that in BD inflammatory monocyte, gene expression is especially elevated while in a mood episode compared to being euthymic.

Keywords: Bipolar disorder, Gene expression, Mood episode, Trait, State

\section{Background}

Disturbances in the immune system have frequently been reported in bipolar disorder (BD) (Leboyer et al. 2012). Several meta-analyses found peripheral cytokines to be raised in patients compared to healthy controls (HC) (Modabbernia et al. 2013; Munkholm et al. 2013). However, the results are heterogeneous, with also studies reporting on normal (Guloksuz et al. 2010) or even lower cytokine levels (Boufidou et al. 2004) in BD compared to

\footnotetext{
*Correspondence: k.becking@umcg.nl

${ }^{\dagger} \mathrm{K}$. Becking and B. C. M. Haarman contributed equally to this work

${ }^{1}$ ICPE/UCP/Triade (CC.72), Interdisciplinary Center Psychopathology

and Emotion Regulation (ICPE), University Medical Center Groningen,

University of Groningen, PO Box 30001, 9700 RB Groningen, The

Netherlands

Full list of author information is available at the end of the article
}

HC. This may be due to the fact that peripheral cytokines are strongly influenced by lifestyle and disease factors (O'Connor et al. 2009). Focusing on the main cellular producers of these cytokines, such as circulating monocytes and macrophages, may be a better approach to find stable markers for BD. Indeed, studies from our group focusing on gene expression of circulating monocytes found a discriminating pro-inflammatory gene expression in BD patients compared to HC (Drexhage et al. 2010; Padmos et al. 2008).

It remains unclear whether these immunological disturbances are related to the mood state, or are a trait phenomenon. Most studies compared BD patients to $\mathrm{HC}$, without differentiating between patients in different mood states. The few available studies that examined immune disturbances across mood states found

\section{贷 Springer}

(c) 2015 Becking et al. This article is distributed under the terms of the Creative Commons Attribution 4.0 International License (http://creativecommons.org/licenses/by/4.0/), which permits unrestricted use, distribution, and reproduction in any medium, provided you give appropriate credit to the original author(s) and the source, provide a link to the Creative Commons license, and indicate if changes were made. 
significantly higher levels of peripheral inflammatory markers during a mood episode compared to euthymia (Barbosa et al. 2014; Brietzke et al. 2009; Cunha et al. 2008; Ortiz-Domínguez et al. 2007; Tsai et al. 2012). Regarding inflammatory gene expression, our original hypothesis prior to the study described below was that monocyte activity might be a diagnostic biomarker for $\mathrm{BD}$ and thus a trait factor. However, in further analysis of our previous study, we already found the expression of specific inflammatory genes to be higher in a small subsample of depressed versus euthymic patients and to a lesser extent in manic compared to euthymic patients (Padmos et al. 2008). Furthermore, we reported a possible relation between a sub-cluster of genes and manic symptomatology (B.C.M. Haarman et al. 2014a) in BD.

In this report, we present the results of the MOODINFLAME study, in which we compared euthymic BD patients with HC. Moreover, we present the results in of a small additional study in which BD patients were compared both in a mood episode and when euthymic. Thus, our study aimed to examine whether inflammatory gene expression in monocytes is a trait or a state marker in BD.

\section{Methods}

\section{Participants}

Data were derived from the EU-funded MOODINFLAME study ("MOODINFLAME website" 2014) carried out to investigate possible inflammatory biomarkers to advance early diagnosis, treatment and prevention of mood disorders. In the MOODINFLAME study, adult male and female subjects were included who were free of inflammation-related symptoms including fever and current or recent infectious or inflammatory disease, uncontrolled systemic disease, uncontrolled metabolic disease or other significant uncontrolled somatic disorders known to affect mood. They did not use somatic medication known to affect mood or the immune system, such as corticosteroids, non-steroid anti-inflammatory drugs and statins. Female candidates who were pregnant or recently gave birth were excluded. The present study has been set up as a cross-sectional case-control study extended with a within-patient longitudinal design. Blood was analyzed of a sample of 159 adult participants recruited from two university psychiatry clinics in Groningen (The Netherlands) and Leuven (Belgium). The sample consisted of $69 \mathrm{HC}, 82$ euthymic $\mathrm{BD}$ patients (BD-Eu) and $8 \mathrm{BD}$ patients with a mood episode (BD-Ep) (seven depressed, one manic). Six of the eight BD-Ep patients were also investigated when they were euthymic ( 6 of the $82 \mathrm{BD}$-Eu patients). Of these patients, one patient was first sampled in an episode and resampled after he was recovered, and the remaining five were first sampled being euthymic and resampled when they became ill again.
The study was approved by the ethical committees of the participating universities, and written informed consent was obtained from all participants.

\section{Assessments}

DSM-IV BD diagnoses were established using the MiniInternational Neuropsychiatric Interview (MINI) (Lecrubier et al. 1997; Sheenan et al. 1998). The severity of depression was measured by the Inventory of Depressive Symptoms (IDS- $\mathrm{C}_{30}$ ) (Rush et al. 1996) for BD patients in a face-to-face interview, for HCs with a self-report questionnaire (IDS-SR 30 ). To determine the presence or intensity of manic symptomatology in patients, the Young Mania Rating Scale (YMRS) (Young et al. 1978) was used. Mood states were defined as euthymic, manic or depressed, based on the MINI. BD-Eu patients were neither in a depressed nor (hypo-)manic episode at the time of measurement as indicated by an IDS- $\mathrm{C}_{30}$ score $<22$ and a YMRS score $<12$, respectively. The remaining clinical characteristics were obtained with the Patient Questionnaire from the former Stanley Foundation Bipolar Network, including separate clinician and patient chapters covering a spectrum of clinical features (Leverich et al. 2001). In the event of a mismatch of results from the MINI in relation to the Patient Questionnaire, diagnoses were checked with the treating physician. Age of onset was defined as the age when the first mood episode occurred, and information on psychiatric medication was dichotomized.

\section{Laboratory methods}

To detect the expression of inflammatory genes of monocytes, similar methods were used as described in the original study by Padmos et al. (2008). In short, RNA was isolated from purified monocytes and to obtain c-DNA for quantitative-polymerase chain reaction (q-PCR), $1 \mu \mathrm{g}$ of RNA was reverse transcribed using the cDNA high-capacity cDNA Reverse Transcription Kit (Applied Biosystems, Carlsbad, CA, USA). Then, relative to the housekeeping gene $\mathrm{ABL} 1$, the expression of $\mathrm{ADM}$, ATF3, BCL2A1, BTG3, CCL2, CCL20, CCL7, CD9, CDC42, CXCL2, DHRS3, DUSP2, EMP1, EREG, FABP5, HSPA1A/HSPA1B, IL-1 $\alpha$, IL-1 $\beta$, IL1R1, IL-6, IRAK2, MAFF, MAPK6, MXD1, NAB2, PDE4B, PTGS2, PTPN7, PTX3, RGCC32, SERPINB2, STX1A, THBD, TNF and TNFAIP3 was determined, using the comparative threshold cycle (CT) method (Biosystems 2001). See Table 1 for the list of genes and corresponding proteins. Data were expressed as $\triangle \mathrm{CT}$ values (values corrected to ABL1) and to control for site (Groningen and Leuven), fold change transformation was applied. By dividing the $\triangle \mathrm{CT}$ scores of patients from Groningen by the mean of healthy controls from Groningen and subsequently the scores of 
Table 1 List of genes with corresponding proteins

\begin{tabular}{|c|c|}
\hline Gene symbol & Name of corresponding protein \\
\hline \multicolumn{2}{|l|}{ Inflammation } \\
\hline ATF3 & Cyclic AMP-dependent transcription factor 3 \\
\hline BCL2A1 & B cell lymphoma-2-related protein A1 \\
\hline CCL20 & C-C chemokine ligand 20 \\
\hline CXCL2 & C-X-C chemokine ligand 2 \\
\hline DUSP2 & Dual specificity protein phosphatase 2 \\
\hline EREG & Epiregulin \\
\hline $\mathrm{IL}-1 \beta$ & Interleukin $1 \beta$ \\
\hline IL-6 & Interleukin 6 \\
\hline PDE4B & cAMP-specific $3^{\prime}, 5^{\prime}$-cyclic phosphodiesterase $4 B$ \\
\hline PTGS2 & Prostaglandin G/H synthase (cyclooxygenase) \\
\hline PTX3 & Pentraxin-related protein 3 \\
\hline TNF & Tumor necrosis factor \\
\hline TNFAIP3 & Tumor necrosis factor, alpha-induced protein 3 \\
\hline \multicolumn{2}{|c|}{ Chemotaxis/adhesion/differentiation/motility } \\
\hline CCL2 & $\mathrm{C}-\mathrm{C}$ chemokine ligand 2 \\
\hline CCL7 & $\mathrm{C}-\mathrm{C}$ chemokine ligand 7 \\
\hline $\mathrm{CDC} 42$ & Cell division control protein 42 homolog \\
\hline DHRS3 & Short-chain dehydrogenase/reductase 3 \\
\hline EMP1 & Epithelial membrane protein 1 \\
\hline MAPK6 & Mitogen-activated protein kinase 6 \\
\hline NAB2 & $\begin{array}{l}\text { Nerve growth factor-induced protein A-binding } \\
\text { protein } 2\end{array}$ \\
\hline PTPN7 & Protein tyrosine phosphatase, non-receptor type 7 \\
\hline STX1A & Syntaxin-1A \\
\hline \multicolumn{2}{|l|}{ Other } \\
\hline ADM & Adrenomedullin \\
\hline BTG3 & BTG family, member 3 \\
\hline CD9 & Cluster of differentiation 9 antigen \\
\hline FABP5 & Fatty acid-binding protein 5 \\
\hline HSPA1/HSPA1B & Heat shock 70 kDa protein 1 \\
\hline$\| \mathrm{L}-1 \alpha$ & Interleukin $1 \alpha$ \\
\hline IL1R1 & Interleukin 1 receptor, type 1 \\
\hline IRAK2 & Interleukin 1 receptor-associated kinase-like 2 \\
\hline MAFF & $\begin{array}{l}\text { Musculoaponeurotic fibrosarcoma oncogene } \\
\text { homolog F }\end{array}$ \\
\hline MXD1 & MAD protein \\
\hline RGCC32 & Regulator of cell cycle \\
\hline SERPINB2 & Plasminogen activator inhibitor-2 \\
\hline THBD & Thrombomodulin \\
\hline
\end{tabular}

patients from Leuven by the mean of healthy controls from Leuven, the relative gene expression was expressed as a fold change (FC) value (Biosystems 2001).

\section{Gene score calculation}

To obtain a simple measure for overall monocyte activation, we calculated a gene score from the expression levels as described by Grosse et al. (2014). For each of the 35 genes, we determined a range in $\mathrm{HC}$ fold change gene expression, defined by the $\mathrm{HC}$ mean \pm 1 standard deviation (SD). Then, we used this range as a standard to compare the gene expression across the different groups. A gene was considered up-regulated if the $\mathrm{FC}$ value was higher than the $\mathrm{HC}$ mean $+1 \mathrm{SD}$, and down-regulated if the FC-value was lower than the HC mean - 1 SD. Then, we calculated a total gene expression score by adding all up-regulated $(+1)$, all down-regulated $(-1)$ and all normally expressed (0) genes for each patient. This method proved to be valid, since the total gene scores showed highly significant correlations with the majority of the genes (Grosse et al. 2014).

Additionally, we calculated two separate sub-cluster gene scores, based on previous cluster analyses performed by Drexhage et al. (2010). The first sub-cluster consisted primarily of pro-inflammatory genes (see Table 1) and the second sub-cluster consisted of chemotaxis, adhesion, differentiation and motility genes (see Table 1).

\section{Statistical analyses}

All data were analyzed with SPSS version 20.0 (SPSS, Chicago, IL, USA). Sample characteristics were compared using Pearson's Chi square and Fisher's exact tests for dichotomous and categorical variables, and for continuous variables ANOVA and $t$ tests were used. To compare inflammatory gene expression scores across HCs, euthymic patients, mood episode patients and within-patient analyses, ANOVA was used. Results were reported as mean \pm standard error. Because only an overall inflammatory gene expression score was used, correction for multiple testing was not applied. As a set of sensitivity analyses, we repeated all analyses using ANCOVA controlling for sex, age and body mass index (BMI).

\section{Results}

Table 2 shows the sample characteristics of $\mathrm{HC}$, BD-Eu patients and BD-Ep patients. Figure 1 shows the total inflammatory gene expression scores in these groups. We found no significant differences between $\mathrm{HC}$ $(2.58 \pm 0.88)$ and BP-Eu (3.48 \pm 0.84$)$, or BD-Ep patients when they were euthymic $(1.17 \pm 0.94)$ (all $p>.44)$. However, BD-Ep patients had a significantly higher total gene expression score $(10.63 \pm 2.58)$ compared to $\mathrm{HC}$ $(p=.004)$ and BD-Eu patients $(p=.009)$ and compared to their own scores when they were euthymic $(p=.020)$. For the means of sub-cluster 1 score, again no significant differences were found between $\mathrm{HC}(1.13 \pm 0.41)$, $\mathrm{BD}-\mathrm{Eu}(1.59 \pm 0.39)$ and BD-Ep patients when they were euthymic $(0.50 \pm 1.38)$ (all $p>.40)$. BP-Ep patients $(5.13 \pm 1.20)$ again had a significantly higher sub-cluster 
Table 2 Characteristics of patients and healthy controls $(N=159)$

\begin{tabular}{|c|c|c|c|c|}
\hline & \multirow[t]{2}{*}{ Healthy controls $(N=69)$} & \multicolumn{2}{|c|}{ Bipolar disorder $(N=90)$} & \multirow[t]{2}{*}{$p^{\mathrm{a}}$} \\
\hline & & Euthymic $(N=82)$ & Mood episode $(N=8)$ & \\
\hline Female, n (\%) & $39(56.5)$ & $41(50.0)$ & $5(62.5)$ & .63 \\
\hline Age, mean (SD) & $44.7(16.1)$ & $43.1(12.1)$ & $41.8(12.7)$ & .72 \\
\hline BMI, mean (SD) & $23.9(3.2)$ & $25.7(4.2)$ & $26.89(4.2)$ & .005 \\
\hline IDS score, mean (SD) & $4.8(3.4)$ & $8.7(8.0)$ & $42.1(14.1)$ & $<.001$ \\
\hline \multicolumn{5}{|l|}{ Clinical characteristics } \\
\hline YMRS score, mean (SD) & - & $1.3(1.2)$ & $4.7(6.4)$ & .001 \\
\hline Bipolar I disorder, $n$ (\%) & - & $53(64.4)$ & $5(62.5)$ & .90 \\
\hline Bipolar II disorder, n (\%) & - & $29(35.4)$ & $3(37.5)$ & \\
\hline Age of onset, mean (SD) & - & $23.3(9.6)$ & $21.8(9.1)$ & .68 \\
\hline Lifetime psychotic features, $n(\%)$ & & $26(31.7)$ & $2(25.0)$ & .70 \\
\hline Psychotropic medication & - & & & \\
\hline Melatonin & - & $1(1.2)$ & $2(25.0)$ & .02 \\
\hline SSRI & - & $4(4.9)$ & $1(12.5)$ & .38 \\
\hline Antipsychotics & - & $14(17.1)$ & $1(12.5)$ & .74 \\
\hline Lithium & - & $62(75.6)$ & $2(25.0)$ & .003 \\
\hline Benzodiazepines & - & $11(13.4)$ & $2(25.0)$ & .37 \\
\hline Antiepileptics & - & $22(26.8)$ & $2(25.0)$ & .91 \\
\hline
\end{tabular}

Differences (italics values) were considered significant if $p<.05$

$S D$ standard deviation, BMI body mass index, IDS Inventory of Depressive Symptoms, YMRS Young Mania Rating Scale, SSRI selective serotonin reuptake inhibitor

${ }^{a}$ Based on $\chi^{2}$ tests and Fisher's exact tests for dichotomous and categorical variables, ANOVA tests when comparing age and BMI, and $t$ tests when comparing continuous variables between euthymic and mood episode BD patients

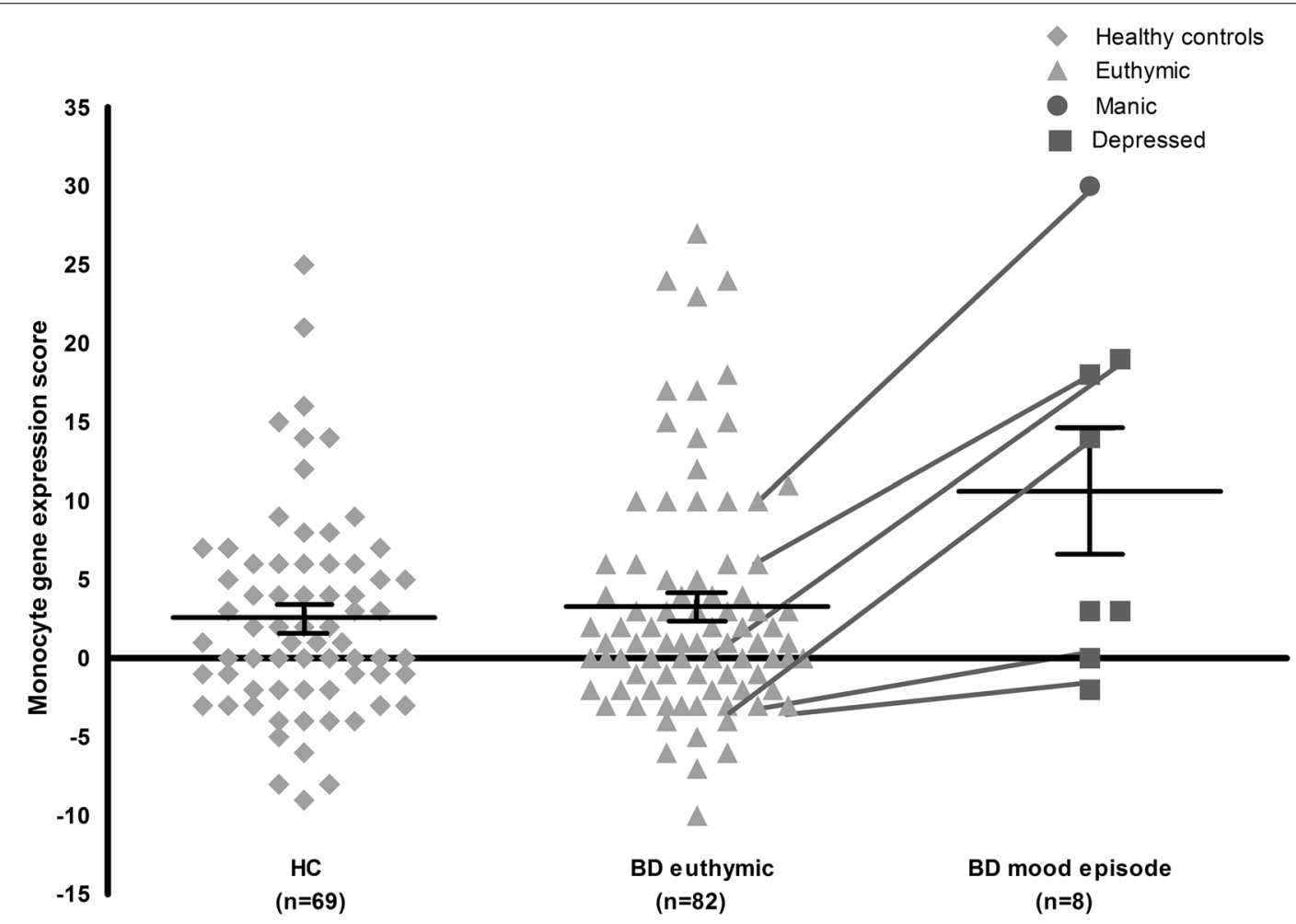

Fig. 1 Total monocyte gene expression score of healthy controls, euthymic and mood episode BD patients $(N=159)$. HC healthy controls, BD bipolar disorder. Black lines represent mean and standard error of the mean per group. Lines connecting values from the BD-Eu and BD-Ep group represent the euthymic patients who were measured again when they had a mood episode 
1 score compared to healthy controls, BD-Eu patients and compared to their own scores when they were euthymic $(p=.002, p=.006$ and $p=.01$, respectively). The mean sub-cluster 2 scores of $\mathrm{HC}(0.74 \pm 0.28)$, BD-Eu patients $(0.59 \pm 0.26)$, BD-Ep patients $(2.0 \pm 0.81)$ and BD-Ep patients when they were euthymic $(0.17 \pm 0.94)$ did not differ significantly between any of the groups (all $p>.10$ ). When repeating the analyses adjusted for sex, age and BMI, this resulted in essentially the same results.

\section{Discussion}

To our knowledge, the present study is the first to show an elevated inflammatory monocyte gene expression in $\mathrm{BD}$ patients when experiencing a mood episode, compared to both $\mathrm{HC}$ and euthymic BD patients. Furthermore, BD-Ep patients had an increased inflammatory gene expression than when they were euthymic. This indicates that inflammatory gene expression in BD is related to the mood state, rather than being a trait marker.

Our findings are supported by several other studies examining peripheral cytokines, where the highest levels of cytokines are found in BD patients with a mood episode, although findings in these studies were not equivocal (Barbosa et al. 2014; Brietzke et al. 2009; Cunha et al. 2008; Ortiz-Domínguez et al. 2007; Tsai et al. 2012). Serum levels of cytokines are known to follow a different pattern than monocyte gene expression (Mesman et al. 2014). Belonging to the same developmental lineage as brain microglia, monocyte activation may be more directly related to psychopathology than circulating cytokines (Beumer et al. 2012; Haarman et al. 2014b).

Previous studies from our group in different samples examining inflammatory monocyte gene expression in relation to $\mathrm{BD}$ found specifically the sub-cluster 2 genes to be related to a mood episode (Drexhage et al. 2010; Padmos et al. 2008) or to severity of manic symptoms (Haarman et al. 2014a). Although in our study the scores were also higher in BD-Ep patients, we did not find a significant difference in sub-cluster 2 gene score compared to $\mathrm{HC}$ or $\mathrm{BD}-\mathrm{Eu}$ patients. This can probably be explained by the fact that we included only one manic patient, whereas in our previous studies more manic patients were included and that we used a total gene score calculation, whereas the previous studies examined the separate genes. Since sub-cluster 2 genes are associated with adhesion, cell differentiation and cell shape changes and sub-cluster 1 consists of the classic pro-inflammatory genes, it seems that in our sample having a mood episode is specifically associated with activation of the inflammatory response system.

Although our finding that an increased inflammatory gene expression is more likely to be a state than a trait phenomenon, the causality and time sequence of these associations are still difficult to interpret. Based on the present data, we cannot be sure whether an increase in inflammatory gene expression preceded the mood episode, or vice versa. In an earlier study, we showed that increased immune activation represented by peripheral markers preceded the onset of manic symptoms in MDD patients (Becking et al. 2013). The only way to examine a clear causal role for immune activation in the development of a mood episode is to measure euthymic patients multiple times prior, during and after a mood episode.

Our study has several limitations. First and most important, although the total sample consisted of 159 persons, we had only few BP-Ep patients: seven patients with a depression and only one manic patient. Since we examined only one manic patient, it is difficult to draw conclusions about inflammatory gene expression in a manic state. However, because we found already significant differences in this small group, we would encourage future studies to include more patients with a mood episode and also to assess patients repeatedly during both an episode and when euthymic. Second, all our patients were treated naturalistically, which resulted in a variety of medications known to influence inflammatory gene expression, including lithium, anticonvulsants, antipsychotics and antidepressants (Haarman et al. 2014a; Padmos et al. 2008; Rybakowski 2000; Tourjman 2012). Since these effects are typically suppressive in nature, medication may have obscured a real difference in inflammatory gene expression between $\mathrm{BD}-\mathrm{Eu}$ patients and $\mathrm{HC}$. However, the BP-Ep patients demonstrating significantly increased gene expression compared to both $\mathrm{HC}$ and $\mathrm{BD}-\mathrm{Eu}$ patients used approximately the same medications, suggesting a pathophysiological cause. Third, our selection of genes was based on the study of Padmos et al. (Padmos et al. 2008) which found these specific signature genes, possibly ruling out other important genes. Finally, our study only focused on inflammatory gene expression of monocytes, which make up around $2-8 \%$ of the total white blood cell population and is still a peripheral measurement. It would also be of interest to examine other parts of the peripheral immune system (e.g., leukocyte subsets), or more proximal factors such as microglial activation in the brain or cytokine concentrations in cerebrospinal fluid.

\section{Conclusions}

In conclusion, our study showed that in BD patients the presence of a mood episode was associated with elevated inflammatory monocyte gene expression. This may imply that immune activation found in BD may occur in episodic patients and not in euthymic patients and can be detected in monocytes. Studies in peripheral cytokines 
corroborate our findings; however, our results in gene expression need to be replicated in larger samples before a firm conclusion can be drawn.

\section{Abbreviations}

BD: bipolar disorder; BD-Ep: bipolar disorder patients with a mood episode BD-Eu: euthymic bipolar disorder patients; BMI: body mass index; CT: comparative threshold; FC: fold change; $\mathrm{HC}$ : healthy control; IDS- $\mathrm{C}_{30}$ : Inventory of Depressive Symptoms, Clinician Rated version; IDS-SR ${ }_{30}$ : Inventory of Depressive Symptoms, Self-Rated version; MINI: Mini-International Neuropsychiatric Interview; RNA: ribonucleic acid; SD: standard deviation; YMRS: Young Mania Rating Scale.

\section{Authors' contributions}

All listed authors concur with the submission; have made a substantial contribution to the analysis and interpretation of the data; the drafting of the article or reviewing it critically; have given final approval of the version of the article to be published and can certify that no other individuals not listed as authors have made substantial contributions to the paper. The authors $\mathrm{BCMH}, \mathrm{KB}$, RFR, HAD, WAN and RS have contributed substantially to the conception and design of the study. The authors BCMH, SC and HAD have made a substantial contribution to the collection of the data. All authors read and approved the final manuscript.

\section{Author details}

${ }^{1}$ ICPE/UCP/Triade (CC.72), Interdisciplinary Center Psychopathology and Emotion Regulation (ICPE), University Medical Center Groningen, University of Groningen, PO Box 30001, 9700 RB Groningen, The Netherlands. ${ }^{2}$ Department of Psychiatry, University Medical Center Groningen, University of Groningen, Groningen, The Netherlands. ${ }^{3}$ Radiology Morphological Solutions, Berkel en Rodenrijs, The Netherlands. ${ }^{4}$ Department of Psychiatry, University of Münster, Münster, Germany. ${ }^{5}$ Department of Psychiatry, University of Leuven (KU Leuven), Louvain, Belgium. ${ }^{6}$ Department of Immunology, Erasmus MC, Rotterdam, The Netherlands.

\section{Acknowledgements}

We thank Harm de Wit and Annemarie Wijkhuijs for their excellent technical assistance and Juliëtte Kalkman for accompanying the patients. This study was funded by EU-FP7-HEALTH-222963'MOODINFLAME' and EU-FP7-PEOPLE286334 'PSYCHAID'. The funding organizations had no further role in the study design; collection, analysis and interpretation of data, the writing of the report and the decision to submit the paper for publication.

\section{Ethics, consent and permissions}

Written informed consent was obtained from all participants.

\section{Compliance with ethical guidelines}

\section{Competing interests}

The authors declare that they have no competing interests.

Received: 25 June 2015 Accepted: 3 September 2015

Published online: 17 September 2015

\section{References}

Barbosa IG, Morato IB, de Miranda AS, Bauer ME, Soares JC, Teixeira AL. A preliminary report of increased plasma levels of IL-33 in bipolar disorder: further evidence of pro-inflammatory status. J Affect Disord. 2014;157:414. doi:10.1016/j.jad.2013.12.042.

Becking K, Boschloo L, Vogelzangs N, Haarman BCM, Riemersma-van der Lek R, Penninx BWJH, Schoevers RA. The association between immune activation and manic symptoms in patients with a depressive disorder. Transl Psychiatry. 2013;3(10):e314. doi:10.1038/tp.2013.87.

Beumer W, Gibney SM, Drexhage RC, Pont-Lezica L, Doorduin J, Klein HC, Drexhage HA. The immune theory of psychiatric diseases: a key role for activated microglia and circulating monocytes. J Leukoc Biol. 2012;92(5):959-75. doi:10.1189/jlb.0212100.

Biosystems A. User bulletin \#2, applied biosystems PRISM 7700 sequence detection system: relative quantitation of gene expression. Appl Biosyst. 2001

Boufidou F, Nikolaou C, Alevizos B, Liappas IA, Christodoulou GN. Cytokine production in bipolar affective disorder patients under lithium treatment. J Affect Disord. 2004;82(2):309-13. doi:10.1016/j.jad.2004.01.007.

Brietzke E, Stertz L, Fernandes BS, Kauer-Sant'anna M, Mascarenhas M, Escosteguy Vargas A, Kapczinski F. Comparison of cytokine levels in depressed, manic and euthymic patients with bipolar disorder. J Affect Disord. 2009;116(3):214-7. doi:10.1016/j.jad.2008.12.001.

Cunha AB, Andreazza AC, Gomes FA, Frey BN, da Silveira LE, Gonçalves CA, Kapczinski F. Investigation of serum high-sensitive $C$-reactive protein levels across all mood states in bipolar disorder. Eur Arch Psychiatry Clin Neurosci. 2008;258(5):300-4. doi:10.1007/s00406-007-0797-0.

Drexhage RC, van der Heul-Nieuwenhuijsen L, Padmos RC, van Beveren N, Cohen D, Versnel MA, Drexhage HA. Inflammatory gene expression in monocytes of patients with schizophrenia: overlap and difference with bipolar disorder. A study in naturalistically treated patients. Int J Neuropsychopharmacol. 2010;13(10):1369-1381. doi:10.1017/ S1461145710000799.

Grosse L, Carvalho LA, Wijkhuijs AJM, Bellingrath S, Ruland T, Ambrée O, Arolt V. Clinical characteristics of inflammation-associated depression: monocyte gene expression is age-related in major depressive disorder. Brain Behav Immun. 2014. doi:10.1016/j.bbi.2014.08.004.

Guloksuz S, Cetin EA, Cetin T, Deniz G, Oral ET, Nutt DJ. Cytokine levels in euthymic bipolar patients. J Affect Disord. 2010;126(3):458-62. doi:10.1016/j.jad.2010.04.027.

Haarman BCM, Riemersma-Van der Lek RF, Burger H, Netkova M, Drexhage RC, Bootsman F, Nolen WA. Relationship between clinical features and inflammation-related monocyte gene expression in bipolar disordertowards a better understanding of psychoimmunological interactions. Bipolar Disord. 2014a;16(2):137-50. doi:10.1111/bdi.12142.

Haarman BCMB, Riemersma-Van der Lek RF, de Groot JC, Ruhé HGE, Klein HC, Zandstra TE, Doorduin J. Neuroinflammation in bipolar disorder-A [(11) C]-(R)-PK11195 positron emission tomography study. Brain Behav Immun. 2014b;40:219-25. doi:10.1016/j.bbi.2014.03.016.

Leboyer M, Soreca I, Scott J, Frye M, Henry C, Tamouza R, Kupfer DJ. Can bipolar disorder be viewed as a multi-system inflammatory disease? J Affect Disord. 2012;141(1):1-10. doi:10.1016/j.jad.2011.12.049.

Lecrubier Y, Sheehan D, Weiller E, Amorim P, Bonora I, Harnett Sheehan K, Dunbar G. The Mini International Neuropsychiatric Interview (MINI). A short diagnostic structured interview: reliability and validity according to the CIDI. Eur Psychiatry 1997;12(5):224-231. doi:10.1016/ S0924-9338(97)83296-8

Leverich GS, Nolen WA, Rush AJ, McElroy SL, Keck PE, Denicoff KD, Post RM. The Stanley Foundation bipolar treatment outcome network. I. Longitudinal methodology. J Affect Disord. 2001;67(1-3):33-44.

Mesman E, Hillegers MH, Ambree O, Arolt V, Nolen WA, Drexhage HA. Monocyte activation, brain-derived neurotrophic factor (BDNF), and S100B in bipolar offspring: a follow-up study from adolescence into adulthood. Bipolar Disord. 2014;1-11. doi:10.1111/bdi.12231.

Modabbernia A, Taslimi S, Brietzke E, Ashrafi M. Cytokine alterations in bipolar disorder: a meta-analysis of 30 studies. Biol Psychiatry. 2013;74(1):15-25. doi:10.1016/j.biopsych.2013.01.007.

MOODINFLAME website. http://moodinflame.eu. 2014

Munkholm K, Braüner JV, Kessing LV, Vinberg M. Cytokines in bipolar disorder vs. healthy control subjects: a systematic review and meta-analysis. Psychiatr Res. 2013;47(9):1119-33. doi:10.1016/j.jpsychires.2013.05.018

O'Connor M-F, Bower JE, Cho HJ, Creswell JD, Dimitrov S, Hamby ME, Irwin MR. To assess, to control, to exclude: effects of biobehavioral factors on circulating inflammatory markers. Brain Behav Immun. 2009;23(7):887-97. doi:10.1016/.j.bbi.2009.04.005.

Ortiz-Domínguez A, Hernandez M, Berlanga C, Gutierez-Mora D, Moreno J, Heinze G, Pavon L. Immune variations in bipolar disorder: phasic differences. Bipolar Disord. 2007;11:596-602.

Padmos RC, Hillegers MHJ, Knijff EM, Vonk R, Bouvy A, Staal FJ, Drexhage HA. A discriminating messenger RNA signature for bipolar disorder formed by an aberrant expression of inflammatory genes in monocytes. Arch Gen Psychiatry. 2008;65(4):395-407. 
Rush AJ, Gullion CM, Basco MR, Jarrett RB, Trivedi MH. The Inventory of Depressive Symptomatology (IDS): psychometric properties. Psychol Med. 1996;26:477-86

Rybakowski J. Antiviral and immunomodulatory effect of lithium. Pharmacopsychiatry. 2000;33(5):159-64.

Sheenan DV, Lecrubier Y, Sheehan H, Amorim P, Janavs J, Weiller E, Dunbar GC. The Mini-International Neuropsychiatric Interview (M.I.N.I.): the development and validation of a structured diagnostic psychiatric interview for DSM-IV and ICD-10. J Clin Psychiatry 1998;59(Suppl 20):22-33.

Tourjman V. In vivo immunomodulatory effects of antipsychotics on inflammatory mediators: a review. Adv Biosci Biotechnol. 2012;03(04):551-65. doi:10.4236/abb.2012.324072.
Tsai S-Y, Chung K-H, Wu J-Y, Kuo C-J, Lee H-C, Huang S-H. Inflammatory markers and their relationships with leptin and insulin from acute mania to full remission in bipolar disorder. J Affect Disord. 2012;136(1-2):110-6. doi:10.1016/j.jad.2011.08.022.

Young RC, Biggs JT, Ziegler VE, Meyer DA. A rating scale for mania: reliability, validity and sensitivity. Br J Psychiatry. 1978;133(5):429-35. doi:10.1192/ bjp.133.5.429.

\section{Submit your manuscript to a SpringerOpen ${ }^{\circ}$ journal and benefit from:}

- Convenient online submission

- Rigorous peer review

- Immediate publication on acceptance

- Open access: articles freely available online

- High visibility within the field

- Retaining the copyright to your article

Submit your next manuscript at $>$ springeropen.com 